\title{
Children's school-breakfast reports and school-lunch reports (in 24-h dietary recalls): conventional and reporting-error-sensitive measures show inconsistent accuracy results for retention interval and breakfast location
}

\author{
Suzanne D. Baxter ${ }^{1 *}$, Caroline H. Guinn ${ }^{1}$, Albert F. Smith ${ }^{2}$, David B. Hitchcock ${ }^{3}$, Julie A. Royer ${ }^{1}$, \\ Megan P. Puryear ${ }^{1}$, Kathleen L. Collins ${ }^{1}$ and Alyssa L. Smith ${ }^{1}$ \\ ${ }^{1}$ Institute for Families in Society, College of Social Work, University of South Carolina, 1600 Hampton Street, Suite 507, \\ Columbia, SC 29208, USA \\ ${ }^{2}$ Department of Psychology, Cleveland State University, Cleveland, OH 44114, USA \\ ${ }^{3}$ Department of Statistics, University of South Carolina, Columbia, SC 29208, USA
}

(Submitted 20 July 2015 - Final revision received 6 December 2015 - Accepted 14 December 2015 - First published online 11 February 2016)

\section{Abstract}

Validation-study data were analysed to investigate retention interval (RI) and prompt effects on the accuracy of fourth-grade children's reports of school-breakfast and school-lunch (in 24-h recalls), and the accuracy of school-breakfast reports by breakfast location (classroom; cafeteria). Randomly selected fourth-grade children at ten schools in four districts were observed eating school-provided breakfast and lunch, and were interviewed under one of eight conditions created by crossing two RIs ('short' - prior-24-hour recall obtained in the afternoon and 'long' - previous-day recall obtained in the morning) with four prompts ('forward' - distant to recent, 'meal name' - breakfast, etc., 'open' - no instructions, and 'reverse' - recent to distant). Each condition had sixty children (half were girls). Of 480 children, 355 and 409 reported meals satisfying criteria for reports of school-breakfast and school-lunch, respectively. For breakfast and lunch separately, a conventional measure report rate - and reporting-error-sensitive measures - correspondence rate and inflation ratio - were calculated for energy per meal-reporting child. Correspondence rate and inflation ratio - but not report rate - showed better accuracy for school-breakfast and school-lunch reports with the short RI than with the long RI; this pattern was not found for some prompts for each sex. Correspondence rate and inflation ratio showed better school-breakfast report accuracy for the classroom than for cafeteria location for each prompt, but report rate showed the opposite. For each RI, correspondence rate and inflation ratio showed better accuracy for lunch than for breakfast, but report rate showed the opposite. When choosing RI and prompts for recalls, researchers and practitioners should select a short RI to maximise accuracy. Recommendations for prompt selections are less clear. As report rates distort validation-study accuracy conclusions, reporting-error-sensitive measures are recommended.

Key words: Children: Schools: Breakfast: Lunch: Dietary recalls

School-provided meals are a major source of food for children in the USA. The average daily participation during the fiscal year 2014 was 13.5 million children for school breakfast and 30.3 million children for school lunch ${ }^{(1)}$. On a given day, $18 \%$ of children attending public schools participated in school breakfast, and $62 \%$ participated in school lunch ${ }^{(2)}$. Child nutrition interventions often target schools ${ }^{(3-8)}$, and dietary recalls have been used to assess intake of children in upper elementary grades $^{(9-16)}$. Of the dietary recall, food diary and FFQ, the dietary recall may be more appropriate for obtaining dietary intake information from elementary-school children as it can be administered without advance notice, and is thus unlikely to alter intake $^{(17)}$, is less burdensome than the food diary ${ }^{(17)}$ and does not require certain cognitive skills (i.e. averaging consumption) required by a $\mathrm{FFQ}^{(18-20)}$. Nevertheless, validation studies show that children's dietary recalls can be substantially inaccurate ${ }^{(21-25)}$. Thus, it is important to investigate methods to improve children's recall accuracy, and to identify conditions in which children's recall accuracy is maximised.

For a 24 -h dietary recall $(24 \mathrm{hDR})$, a respondent is to report all foods and drinks consumed during a 24-h period; the recall may be obtained in person, by telephone or by automated selfadministration $^{(26)}$. Prominent $24 \mathrm{hDRs}$ are multiple-pass procedures, with several passes to elicit reports of different aspects of intake for the target $24 \mathrm{~h}$. The United States Department of Agriculture originally developed the multiple-pass $24 \mathrm{hDR}$

Abbreviations: 24hDR, 24-h dietary recall; RI, retention interval.

* Corresponding author: S. D. Baxter, fax +1 803777 1120, email sbaxter@mailbox.sc.edu 
method $^{(27)}$. In passes one through five, respectively, a respondent lists all foods consumed in a $24-\mathrm{h}$ period; an interviewer elicits additional recall by asking about nine categories of foods that are often forgotten; the interviewer collects the time at which each food was eaten and the name of the eating occasion; in chronological order by eating occasion, the interviewer collects details of, and additions to, each food, amount eaten, source (e.g. restaurant or store), and whether it was eaten at home, and then reviews each eating occasion and interval between occasions to elicit additional recall; and the interviewer provides a final opportunity to recall foods ${ }^{(27)}$.

There are various ways to specify the target $24 \mathrm{~h}$ for a $24 \mathrm{hDR}$ (e.g. prior $24 \mathrm{~h}$ (immediately before the interview), or previous day (midnight to midnight of the day before the interview)). For any such specification, a $24 \mathrm{hDR}$ may occur at any time of the day (e.g. morning, afternoon or evening). Choices of target period and interview time determine the elapsed time between the to-be-reported meals and interview, referred to as retention interval (RI). Studies with children in the USA (Georgia and South Carolina) and Wales have shown that dietary recall accuracy decreases as the RI increases ${ }^{(28-34)}$.

In addition to RI, any $24 \mathrm{hDR}$ has prompts - questions asked in the first pass of a multiple-pass $24 \mathrm{hDR}$ to elicit a respondent's report. As examples, a respondent may be prompted to report intake for the target period in forward order (beginning to end), in reverse order (end to beginning), by meal name (e.g. breakfast, lunch, etc.) or with open prompts (no specific instructions). Prompts may influence recall accuracy, but few validation studies have examined this relationship ${ }^{(25,35)}$. For a recent validation study ${ }^{(36)}$, we examined the effects of prompts on children's dietary recall accuracy for school meals, and assessed whether and how the effects of prompts depended on RI.

Dietary recall procedures ask where reported meals were eaten, and recall accuracy is plausibly related to eating location, or variability of eating locations. Our validation study conducted in schools permits investigation of the role of meal location in recall accuracy. In some schools, breakfast is provided and consumed in classrooms; in other schools, breakfast is provided and consumed in the school cafeteria. Children's breakfast accuracy may be better for classroom than for cafeteria breakfast because location cues could help discriminate classroom breakfast from lunch, located in the cafeteria.

Dietary recall accuracy in validation studies has usually been assessed by transforming reference (e.g. observed) and reported sets of foods to energy and/or nutrients and comparing these ${ }^{(37)}$. Using this 'conventional' approach, reported items are transformed into energy and/or nutrients without regard to whether those items were actually eaten, or determining the amount of each reported item that was actually eaten. Conventional 'accuracy' is measured by report rate - the ratio of reported kilocalories to reference kilocalories - with report rates about $100 \%$ interpreted as accurate. However, reported kilocalories include not only kilocalories from items reported eaten that were eaten, but also kilocalories from over-reported amounts of items eaten, and kilocalories from items not eaten. We used these three categories of reported kilocalories, along with reference kilocalories, to calculate two 'reporting-error-sensitive' measures - correspondence rate and inflation ratio ${ }^{(37)}$. Correspondence rate quantifies the match between kilocalories from items reported and kilocalories observed eaten; inflation ratio quantifies over-reporting relative to what was observed eaten. (For any analysed meal, the sum of the correspondence rate and the inflation ratio is the report rate.)

Most publications about validation studies that have used direct observations of school breakfast and school lunch to examine children's dietary recall accuracy have provided results for the two meals combined, as we did for our recently completed study of the effects of prompts on children's dietary recall accuracy, and whether and how prompts' effects depended on $\mathrm{RI}^{(36)}$. However, examining accuracy for individual meals can be informative, revealing, for example, particular ways in which reports of different meals differ systematically. In this article, we used data from that study to investigate factors that influence reports of school breakfast and of school lunch, and also compared the pictures of recall accuracy provided by conventional and error-sensitive measures. Our first goal for this article was to examine separately the relationship of accuracy of children's school-breakfast reports and school-lunch reports in $24 \mathrm{hDRs}$ to the variables manipulated in the study. Our second goal was to compare the accuracy of reports for school breakfast located in the classroom and in the cafeteria.

\section{Methods}

The study was conducted according to the guidelines laid down in the Declaration of Helsinki and all procedures involving human subjects were approved by the University of South Carolina human subjects review board. Written informed parental consent and child assent were obtained from all subjects. The sample size estimation, sample and data collection methods have been described in detail elsewhere ${ }^{(36)}$, and thus only a summary is provided here.

\section{Sample size}

Power calculations were based on the methodologies of Neter et $a l .{ }^{(38)}$ and Winer ${ }^{(39)}$. The required sample sizes were estimated by using rates for omissions (items observed eaten but not reported eaten) and intrusions (items reported eaten but not observed eaten) from school-meal reports in fourth-grade children's $24 \mathrm{hDR}$ in past studies ${ }^{(25,28,32)}$. Assuming $\alpha=0 \cdot 025$, we determined that a total of 480 children, with thirty children in each of sixteen cells (two RIs $\times$ four prompts $\times$ two sexes), were required to detect main effects, two-way interactions and the three-way interaction with power of at least 0.77 for even the smallest effect size of interest.

\section{Sample}

Data were collected on fourth-grade children during three school years (2011-2012, 2012-2013 and 2013-2014). Children were from all regular fourth-grade classes from a total of ten public schools from four school districts. At these schools, for 
the three respective school years, the percentage of children eligible for free or reduced-price school meals ranged from 69 to 85,58 to 90 and 59 to $90 \%$. Of 569, 782 and 429 children invited to participate for the three respective school years, $407(71.5 \%), 521$ (66.6\%) and 280 (65.3\%) agreed. Each school year, distributions of race/ethnicity and sex of the children who agreed to participate were similar to those of children invited. For the three respective school years, data were collected in six, ten and five schools (twenty-six, thirty-eight and twenty-one classes).

Each district had implemented offer $v$. serve food service, and thus at each school, of the meal components available at each meal, children could refuse one at breakfast, and one or two at lunch, but had to select a fruit or vegetable at each meal ${ }^{(40)}$. A standard breakfast included fruit, grains and milk, whereas a standard lunch included meat or alternate, grains, fruit, vegetable and milk ${ }^{(40)}$; children had a choice of food items (e.g. fruit, juice, milk flavour, vegetable, entrée) at most meals. In the 3 consecutive years, breakfast was located in the classroom for all classes at two, two and two schools, respectively, and in the cafeteria for all classes at four, seven and three schools, respectively. For one school during the 2012-2013 school year, breakfast was in the cafeteria for all classes but one; some children in that class ate breakfast in the cafeteria, whereas others ate in the classroom. Breakfast locations were designated by school principals and were constant throughout a school year. For the three respective school years of data collection, at the schools in the study where breakfast was located in the cafeteria, the percentage of children eligible for free or reduced-price school meals ranged from 69 to 85,58 to 90 and 71 to $90 \%$; at the schools in the study where breakfast was located in the classroom, the respective values ranged from 74 to 81,60 to 82 and 59 to $82 \%$. Lunch was located in the cafeteria for all classes at all schools for all school years. Participation in breakfast, regardless of location, and participation in lunch, were optional for each child at each school. Research has shown that participation in school breakfast is related to location, with higher participation rates for classroom than for cafeteria breakfast ${ }^{(41,42)}$

Data were collected until 480 children, randomly selected from the pool of consented children each school year with the constraint that half were girls, were observed eating schoolprovided breakfast and lunch (with both meals observed on the same day for any child), with sixty (half were girls) interviewed to obtain a $24 \mathrm{hDR}$ in each of the eight protocol conditions formed by crossing two RIs ('short' - prior-24-h recall obtained in the afternoon and 'long' - previous-day recall obtained in the morning) with four prompts (forward, meal name, open and reverse). Within school year and school, assignment to condition (by sex) was balanced across classes as much as possible.

\section{Direct meal observations}

Research staff observed children eating school breakfast and school lunch according to a standard protocol. One of three observers watched one to three children simultaneously, and, on a paper form, noted items and amounts eaten in servings of standard school meal portions. Observers were present during the entire meal period so that any food trades could be noted $^{(23,43)}$. For breakfast located in the classroom, children ate at their desks. For breakfast and lunch in the cafeteria, children sat according to the school's typical arrangement. Interobserver reliability was assessed before and throughout data collection each school year; mean agreement between observers to within one-fourth of a serving on amounts eaten was $\geq 97 \%$, which is considered excellent ${ }^{(44,45)}$

\section{Dietary recall interviews}

To obtain $24 \mathrm{hDR}$, one of four research staff interviewed children (without parental assistance) in person in private at school during the school day, using the protocol for the condition to which the child had been assigned. All interviews were conducted on Tuesdays through Fridays. Interviews concerning the previous day (long RI) were conducted after breakfast, and interviews concerning the prior $24 \mathrm{~h}$ (short RI) were conducted after lunch. (Thus, each long RI interview occurred approximately $25 \mathrm{~h}$ after the target breakfast and $21 \mathrm{~h}$ after the target lunch, with a non-target breakfast intervening between the end of the target period and the interview. Each short RI interview occurred approximately $5 \mathrm{~h}$ after the target breakfast and $1 \mathrm{~h}$ after the target lunch, with no intervening, non-target meals before the interview.) For prior-24-h-afternoon interviews, children were asked to report intake first for the interview day, and then for the previous day beginning $24 \mathrm{~h}$ before the interview start time. This approach, proposed by Buzzard ${ }^{(46)}$, has been used previously with children ${ }^{(28-32)}$. For each child, different researchers observed meals and conducted the interview.

Training for interviewers included modelling, practice and assessment of pre-data-collection quality control for interviews. Children reported amounts eaten in qualitative terms (e.g. little bit, half, most), and interviewers wrote information reported by children on paper forms. Interviews were audio-recorded and transcribed. Each interviewed child was mailed a $\$ 10$ cheque. For each interview, quality control was assessed using established procedures ${ }^{(25,28-30,32,47,48)}$ to ascertain that the interviewer adhered to the protocol; only interviews that passed quality control were analysed.

\section{Analyses}

Analyses were limited to school meals in $24 \mathrm{hDRs}$ because only those meals were validated using direct meal observation by research staff. As in past studies ${ }^{(22,25,28-30,32,47)}$, for a meal reported in a $24 \mathrm{hDR}$ to be counted as a school meal, the child had to refer to breakfast as 'breakfast' or 'school breakfast' and to lunch as 'lunch' or 'school lunch', the reported location had to be 'school', and the reported mealtime had to be within $1 \mathrm{~h}$ of the observed mealtime.

To quantify recall accuracy, for each child, for each school meal reported, an established system ${ }^{(22,25,28-30,32,47)}$ was used to compare the set of food items and amounts reported eaten with the set of food items and amounts observed eaten. Each food item was classified as a match (item observed eaten and reported eaten), an omission (item observed eaten but not 
reported eaten) or an intrusion (item reported eaten but not observed eaten) ${ }^{(49,50)}$.

Amounts eaten were observed, reported and scored in servings of standard school meal portions as none $=0 \cdot 00$, taste $=$ $0 \cdot 10$, little bit $=0 \cdot 25$, half $=0 \cdot 50$, most $=0.75$, all $=1.00$ or the actual number of servings if $>1.00$ serving was observed and/or reported eaten. Information on energy (in kilocalories) for each observed and/or reported item was obtained from the University of Minnesota's Nutrition Coordinating Center Food and Nutrient Database ${ }^{(51)}$. For observed and reported items for each meal for each child, quantified servings were multiplied by perserving kilocalories.

For breakfast and lunch separately, a conventional energy measure - report rate - was calculated. Report rate is the reported percentage of the observed energy; it was calculated for each child as (total reported kilocalories/total observed kilocalories $) \times 100$. A report rate of $0 \%$ indicates that nothing was reported eaten at a school meal. Report rate has no maximum value, because there is no limit on what a person can report. Traditional interpretation of report rate is that values close to $100 \%$ indicate high accuracy, values $>100 \%$ indicate over-reporting and values $<100 \%$ indicate underreporting $^{(24,52,53)}$.

Also, for breakfast and lunch separately, two reporting-errorsensitive energy measures - correspondence rate and inflation ratio - were calculated ${ }^{(37,54-56)}$. Correspondence rate is the percentage of the observed kilocalories that are reported correctly; it was calculated for each child as (sum of corresponding kilocalories from matches/sum of observed kilocalories) $\times 100$. Corresponding kilocalories from a match are the smaller of the reported kilocalories and the observed kilocalories. A correspondence rate is between $0 \%$, which indicates that no items observed eaten were reported eaten, and $100 \%$, which indicates that all items observed eaten were reported eaten, and that all amounts reported eaten were at least as large as amounts observed eaten. Higher correspondence rates indicate better accuracy.

Inflation ratio, a measure of reporting error, indicates the extent to which over-reported kilocalories augment correctly reported kilocalories; it was calculated for each child as ((Coverreported kilocalories from matches $)+($ kilocalories from intrusions) $) /($ total observed kilocalories $))) \times 100$. An inflation ratio of $0 \%$ indicates that there were no intrusions and that no amounts of matches were over-reported. Inflation ratio has no maximum value because there is no limit on what a person can report. Smaller inflation ratios indicate better accuracy. For any child for any meal, correspondence rate and inflation ratio sum to report rate.

Data were pooled over three school years for analyses. For each meal, we used $\chi^{2}$ tests of homogeneity to investigate whether the proportions of children reporting meals that satisfied criteria (to be reports of school meals) varied over levels of RI, prompt, sex and breakfast location.

For breakfast, for report rate as well as for correspondence rate and for square-root-transformed inflation ratio, we used a linear model to ascertain main effects of RI, prompt, sex and breakfast location, their two-way interactions, and the threeway interaction of RI, prompt and sex. For lunch, except for breakfast location, linear models were identical. Control variables were race/ethnicity, school year and district. The transformation of inflation ratio was to help satisfy the normality assumption.

For these linear models, we used generalised estimating equation methodology to account for possible correlation in response values within the same interviewer; an exchangeable correlation structure was assumed. For all models, analysis of residuals was used to check assumptions of constant error variance and normality of errors. We used simultaneous Wald's tests to jointly test for factor effects in each model, and the Benjamini-Hochberg procedure ${ }^{(57)}$ to adjust for simultaneous tests on multiple factors and in multiple models, controlling the false discovery rate at $0 \cdot 05$. All $P$ values reported are adjusted. Statistical analyses used SAS/STAT ${ }^{\circledR}\left(9.4^{\circledR}\right.$ 2002-2012; SAS Institute Inc.).

\section{Results}

The 480 children interviewed were 54\% African American, $31 \%$ white, $10 \%$ Hispanic and 5\% other; their mean age was 10 years and 1 month. Of these children, 245 ate school breakfast in cafeterias and 235 ate school breakfast in their classrooms.

\section{Reporting meals that satisfied criteria to be reports of school meals}

A total of 125 children reported no meal that met the criteria to be a report of school breakfast; seventy-one children reported no meal that met the criteria to be a report of school lunch. (In all, twenty-five children are common to these two sets.) We call these children 'non-reporters' (for these meals); we call children whose reports satisfied criteria to be reports of school meals 'reporters'.

Table 1 shows, for each meal, the distribution of meal nonreporters by RI, prompt, sex and breakfast location. A larger proportion of non-reporters than reporters were in the long RI than in the short RI; this was marginally significant for breakfast $\left(\chi^{2}=3.13, \quad P=0.08\right)$ and significant for lunch $\left(\chi^{2}=8.75\right.$, $P=0.003)$. For breakfast, a higher proportion of reporters than non-reporters had forward and meal prompts than open and reverse prompts $\left(\chi^{2}=7.99, \quad P=0.046\right)$. For lunch, mealreporting status was not associated with prompt $\left(\chi^{2}=2 \cdot 96\right.$, $P=0 \cdot 40)$. Meal-reporting status was not associated with sex (breakfast $\chi^{2}=0.27, P=0.60$; lunch $\chi^{2}=1 \cdot 34, P=0 \cdot 25$ ). For breakfast, meal-reporting status was not associated with breakfast location $\left(\chi^{2}=0 \cdot 06, P=0 \cdot 80\right)$.

Of the 125 school-breakfast non-reporters, (a) forty-two children (34\%) failed to report any breakfast, (b) twenty-four children (19\%) failed to report 'school' as the breakfast location (with twenty-two of twenty-four reporting 'home' as the breakfast location), (c) twenty-six children (21\%) failed to report the school-breakfast mealtime within $1 \mathrm{~h}$ of the observed mealtime and (d) thirty-three children (26\%) failed to report 'school' as the breakfast location and failed to report the schoolbreakfast mealtime within $1 \mathrm{~h}$ of the observed mealtime (with six of thirty-three reporting $>1$ breakfast). Of the seventy-one 
Table 1. Number of children who did not report any meal to satisfy criterion to be considered school breakfast $(n 125)$ or school lunch $(n 71)$ for eight conditions created by crossing two retention intervals (RI) with four prompts from a validation study with 480 fourth-grade children

\begin{tabular}{|c|c|c|c|c|c|}
\hline & $\begin{array}{l}\text { Forward } \\
\text { prompts }\end{array}$ & $\begin{array}{l}\text { Meal name } \\
\text { prompts }\end{array}$ & $\begin{array}{c}\text { Open } \\
\text { prompts }\end{array}$ & $\begin{array}{l}\text { Reverse } \\
\text { prompts }\end{array}$ & $\begin{array}{l}\text { Total } \\
(n)\end{array}$ \\
\hline \multicolumn{6}{|l|}{ Breakfast } \\
\hline \multicolumn{6}{|l|}{ Short RI } \\
\hline Girls & 8 & 7 & 7 & 7 & 29 \\
\hline Boys & 4 & 5 & 9 & 7 & 25 \\
\hline Short RI total $(n)$ & 12 & 12 & 16 & 14 & 54 \\
\hline \multicolumn{6}{|l|}{ Long RI } \\
\hline Girls & 5 & 9 & 9 & 8 & 31 \\
\hline Boys & 7 & 4 & 14 & 15 & 40 \\
\hline Long RI total $(n)$ & 12 & 13 & 23 & 23 & 71 \\
\hline Overall total $(n)$ & 24 & 25 & 39 & 37 & 125 \\
\hline \multicolumn{6}{|c|}{ Breakfast location - classroom } \\
\hline \multicolumn{6}{|l|}{ Short RI } \\
\hline Girls & 5 & 3 & 2 & 2 & 12 \\
\hline Boys & 2 & 2 & 6 & 4 & 14 \\
\hline Short RI total $(n)$ & 7 & 5 & 8 & 6 & 26 \\
\hline \multicolumn{6}{|l|}{ Long RI } \\
\hline Girls & 2 & 6 & 4 & 3 & 15 \\
\hline Boys & 4 & 1 & 4 & 10 & 19 \\
\hline Long RI total $(n)$ & 6 & 7 & 8 & 13 & 34 \\
\hline Overall total $(n)$ & 13 & 12 & 16 & 19 & 60 \\
\hline \multicolumn{6}{|c|}{ Breakfast location - cafeteria } \\
\hline \multicolumn{6}{|l|}{ Short RI } \\
\hline Girls & 3 & 4 & 5 & 5 & 17 \\
\hline Boys & 2 & 3 & 3 & 3 & 11 \\
\hline Short RI total $(n)$ & 5 & 7 & 8 & 8 & 28 \\
\hline \multicolumn{6}{|l|}{ Long RI } \\
\hline Girls & 3 & 3 & 5 & 5 & 16 \\
\hline Boys & 3 & 3 & 10 & 5 & 21 \\
\hline Long RI total $(n)$ & 6 & 6 & 15 & 10 & 37 \\
\hline Overall total $(n)$ & 11 & 13 & 23 & 18 & 65 \\
\hline \multicolumn{6}{|l|}{ Lunch } \\
\hline \multicolumn{6}{|l|}{ Short RI } \\
\hline Girls & 3 & 3 & 3 & 5 & 14 \\
\hline Boys & 2 & 4 & 1 & 3 & 10 \\
\hline Short RI total $(n)$ & 5 & 7 & 4 & 8 & 24 \\
\hline \multicolumn{6}{|l|}{ Long RI } \\
\hline Girls & 6 & 5 & 2 & 4 & 17 \\
\hline Boys & 11 & 3 & 8 & 8 & 30 \\
\hline Long RI total $(n)$ & 17 & 8 & 10 & 12 & 47 \\
\hline Overall total $(n)$ & 22 & 15 & 14 & 20 & 71 \\
\hline
\end{tabular}

Forward prompts, distant to recent; meal name prompts, breakfast, lunch, etc.; open prompts, no specific instructions; reverse prompts, recent to distant; short RI, recal in the afternoon about the prior $24 \mathrm{~h}$ intake; long $\mathrm{Rl}$, recall in the morning about the previous day's intake.

school-lunch non-reporters, (a) twenty-three children (32\%) failed to report any lunch, (b) one child failed to report 'school' as the lunch location, (c) forty-one children (58\%) failed to report the school-lunch mealtime within $1 \mathrm{~h}$ of the observed mealtime (with eight of forty-one reporting $>1$ lunch), and (d) seven children (10\%) failed to report 'school' as the lunch location and failed to report the school-lunch mealtime within $1 \mathrm{~h}$ of the observed mealtime.

In analyses of report rate, correspondence rate and inflation ratio described in subsequent sections, we did not include the 125 breakfast non-reporters, nor the seventy-one lunch nonreporters. Our rationale to not include them in analyses is as follows: for these children for these meals, the value of each of report rate, correspondence rate and inflation ratio was $0 \%$.
These values satisfy the intuition that, for these children, the value of report rate should indicate (maximal) under-reporting and the value of correspondence rate should indicate maximum error. However, a $0 \%$ inflation ratio indicates maximum accuracy for the aspect of performance that it quantifies (i.e. it indicates that nothing that should not have been reported was reported), which conflicts with intuition. Although one might argue that meal non-reporters should be included in the analyses of report rate and correspondence rate, including them in analyses of inflation ratio would overestimate reporting accuracy by children in the sample.

\section{Report rate}

As explained earlier, report rate is total reported kilocalories divided by total observed kilocalories. We use customary interpretation to describe results, with values closest to $100 \%$ as indicating accurate reporting, values $>100 \%$ as indicating overreporting and values $<100 \%$ as indicating under-reporting.

Breakfast. Table 2 shows least squares means for breakfast report rate by RI, prompt, sex and location. The main effects of prompt $(P<0.0003)$ and location $(P<0.0019)$ were significant; these effects must be understood within the context of significant RI $\times$ prompt $(P<0.0003)$, prompt $\times$ sex $(P<0.0003), \mathrm{RI} \times \operatorname{prompt} \times \operatorname{sex}$ $(P=0.0011)$ and prompt $\times$ location $(P=0.0141)$ interactions. Not significant were the main effects of RI $(P=0.92)$ and sex $(P=0.92)$, and the RI $\times \operatorname{sex}(P=0.89), \mathrm{RI} \times$ location $(P=0.89)$ and sex $\times$ location $(P=0 \cdot 46)$ interactions.

The three-way interaction was due to different patterns of report rates by the two sexes over the four prompts at the two RIs. With the short RI, girls' breakfast report rate was most accurate with forward (98.9\%), over-reported with open (113.1\%) and under-reported with meal name (89.9\%) and reverse (91.5\%) prompts, whereas boys' report rate was most accurate with meal name $(101 \cdot 8 \%)$, over-reported with reverse (113.4\%) and underreported with forward (94.5\%) and open (85.7\%) prompts. With the long RI, girls' breakfast report rate was most accurate with open (108.1\%), over-reported with reverse (126.7\%) and underreported with meal name (77.8\%) and forward (84.6\%) prompts, whereas boys' report rate was most accurate with forward (97.1\%) and meal name (99.0\%), over-reported with reverse (129.5\%) and under-reported with open $(55 \cdot 2 \%)$ prompts.

Analyses of these data indicated over-reporting for breakfast located in the cafeteria (118.3\%) and under-reporting for breakfast located in the classroom $(77 \cdot 6 \%)$. The prompt $\times$ location interaction indicated variation in the size of the difference over the four prompts. Breakfast report rates (cafeteria, classroom) by prompt were as follows: forward (108.6, 79.0\%), meal name (105.3, $79 \cdot 0 \%)$, open (116.8, 64.3\%) and reverse (142.6, 88.0\%).

It is noteworthy that, overall, breakfast report rate was unrelated to RI. Averaging across all other variables, breakfast report rate for the short RI was $98.6 \%$ and for the long RI was $97.3 \%$ - these values are conventionally interpreted as accurate.

Lunch. Table 2 also shows least squares means for lunch report rate by RI, prompt and sex. The main effects of prompt and sex 


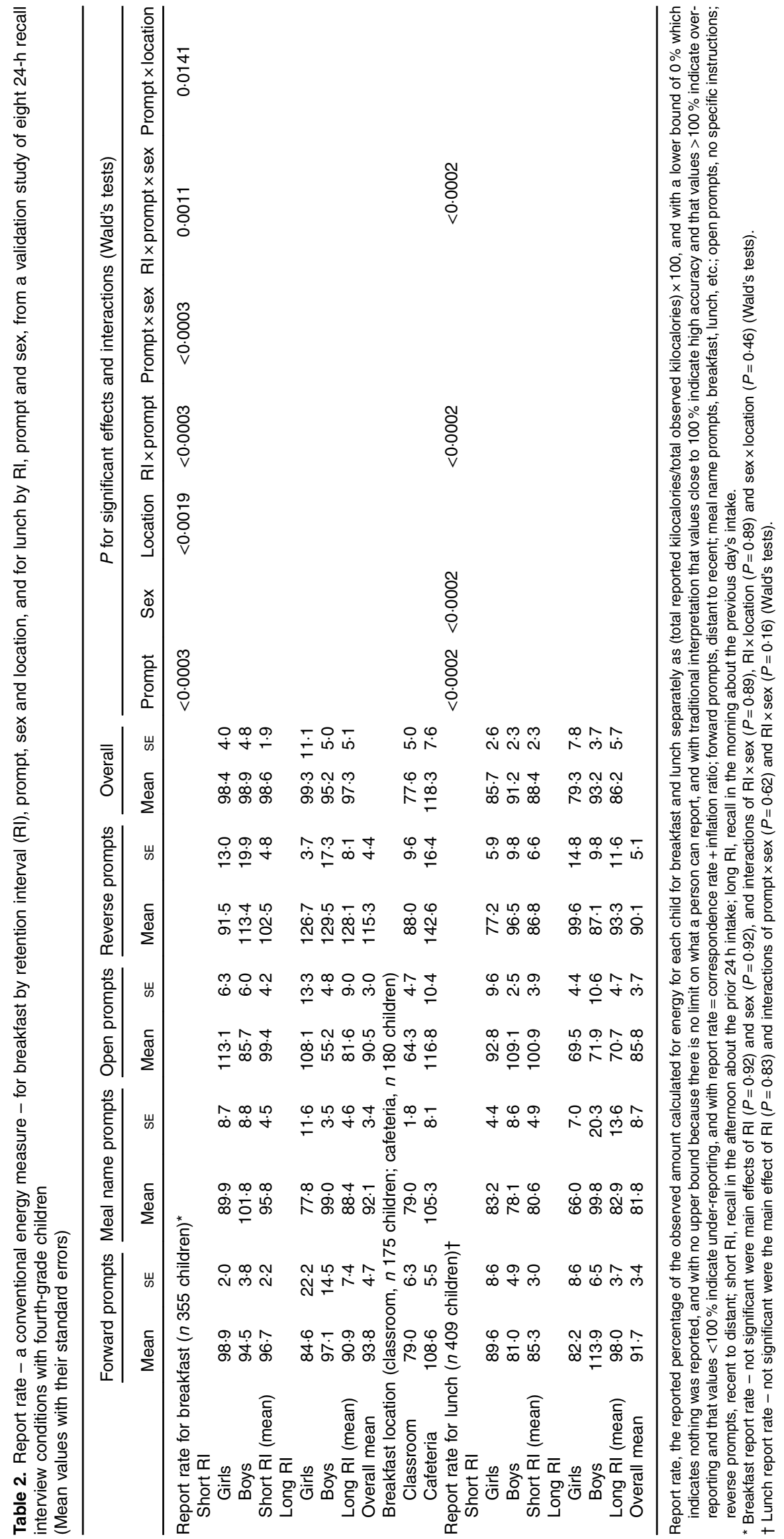


were significant, as were the RI $\times$ prompt and RI $\times$ prompt $\times$ sex interactions (four $P$-values $<0.0002$ ). Not significant were the main effect of RI $(P=0.83)$ and the prompt $\times \operatorname{sex}(P=0.62)$ and $\mathrm{RI} \times \operatorname{sex}(P=0 \cdot 16)$ interactions. For the three-way interaction, with the short RI, girls' lunch report rate was most accurate with open $(92 \cdot 8 \%)$ and forward (89.6\%) prompts, not over-reported for any of the four prompts, and under-reported with meal name $(83.2 \%)$ and reverse $(77.2 \%)$ prompts, whereas boys' lunch report rate was most accurate with reverse (96.5\%), overreported with open $(109 \cdot 1 \%)$ and under-reported with forward $(81.0 \%)$ and meal name $(78.1 \%)$ prompts. With the long RI, girls' lunch report rate was most accurate with reverse (99.6\%), not over-reported for any of the four prompts, and underreported with forward $(82 \cdot 2 \%)$, meal name $(66.0 \%)$ and open (69.5\%) prompts, whereas boys' lunch report rate was most accurate with meal name (99.8\%), over-reported with forward $(113.9 \%)$ and under-reported with open $(71.9 \%)$ and reverse $(87 \cdot 1 \%)$ prompts.

It is noteworthy that, as for breakfast report rate, the effect of RI on lunch report rate was not significant. Averaging across all other variables, lunch report rate for the short RI was $88.4 \%$ and for the long RI was $86 \cdot 2 \%$.

\section{Correspondence rate}

Correspondence rate indicates the extent to which kilocalories from items reported eaten match kilocalories observed eaten; it is the ratio of matching kilocalories to observed kilocalories. As explained earlier, a correspondence rate is between 0 and $100 \%$. Higher values indicate better accuracy.

Breakfast. Table 3 shows least squares means for breakfast correspondence rate by RI, prompt, sex and location. The main effects of RI, prompt and location were significant, as were interactions of $\mathrm{RI} \times$ prompt, prompt $\times$ sex and $\mathrm{RI} \times$ prompt $\times$ sex (six $P$-values $<0.0003)$. Not significant was the main effect of $\operatorname{sex}(P=0.89)$ and the $\mathrm{RI} \times \operatorname{sex}(P=0.98), \mathrm{RI} \times$ location $(P=0.71)$ and sex $\times$ location $(P=0.98)$ interactions. The prompt $\times$ location $(P=0.0556)$ interaction was not quite significant, using a significance level that controls the false discovery rate at 0.05 .

On average, breakfast correspondence rate was higher with the short $(67.2 \%)$ than with the long $(42.4 \%)$ RI. For the threeway interaction, with the short RI, girls' breakfast correspondence rate was highest with forward (78.0\%) and reverse $(72 \cdot 4 \%)$ prompts and lowest with meal name (60.2\%) and open (62.3\%) prompts, whereas boys' breakfast correspondence rate was highest with reverse $(75.7 \%)$ and lowest with forward (58.2\%) and meal name (60.9\%) prompts. With the long RI, girls' breakfast correspondence rate was highest with meal name $(55.9 \%)$ and lowest with open (32.5\%) prompts, whereas boys' breakfast correspondence rate was highest with reverse (53.4\%) and forward (49.9\%) prompts and lowest with meal name $(31.7 \%)$ and open $(30.0 \%)$ prompts.

Breakfast correspondence rates were higher for breakfast located in the classroom (61.9\%) than for breakfast in the cafeteria $(47.7 \%)$. Although the prompt $\times$ location interaction was not significant at the 0.05 level, there was some evidence of variation in the classroom advantage over the four prompts. Breakfast correspondence rates (classroom, cafeteria) by prompt were as follows: forward $(60 \cdot 9,50 \cdot 5 \%)$, meal name $(65 \cdot 8,38 \cdot 6 \%)$, open $(53 \cdot 8,43 \cdot 7 \%)$ and reverse $(67 \cdot 0,58 \cdot 0 \%)$.

Lunch. Table 4 shows least squares means for lunch correspondence rate by RI, prompt and sex. The main effects of RI and prompt were significant, as was the interaction of RI $\times$ prompt (three $P$-values $<0.0002)$. Not significant was the main effect of $\operatorname{sex}(P=0 \cdot 94)$ and the prompt $\times \operatorname{sex}(P=0 \cdot 20), \mathrm{RI} \times \operatorname{sex}$ $(P=0.46)$ and $\mathrm{RI} \times$ prompt $\times \operatorname{sex}(P=0.84)$ interactions. On average, lunch correspondence rate was higher with the short (70.6\%) than with the long (53.2\%) RI. For the RI $\times$ prompt interaction, with the short RI, lunch correspondence rate was highest with open (76.1\%) and lowest with meal name (66.9\%) prompts, whereas with the long RI, lunch correspondence rate was highest with reverse $(67.4 \%)$ and lowest with meal name $(45 \cdot 8 \%)$ and open $(47 \cdot 0 \%)$ prompts.

\section{Inflation ratio}

Inflation ratio indicates the extent to which reported kilocalories do not match kilocalories observed eaten; it is the ratio of reported non-matching kilocalories to observed kilocalories. Higher values indicate more error.

Breakfast. Table 3 also shows least squares means for breakfast inflation ratio by RI, prompt, sex and location. The main effects of RI and location were significant, as were the RI $\times$ prompt, prompt $\times$ sex, RI $\times$ prompt $\times$ sex (five $P$-values $<0.0007$ ) and prompt $\times$ location $(P=0.0016)$ interactions. Not significant were the main effects of prompt $(P=0.49)$ and sex $(P=0.89)$, and the $\mathrm{RI} \times \operatorname{sex}(P=0.89), \mathrm{RI} \times$ location $(P=0.92)$ and $\operatorname{sex} \times$ location $(P=0.89)$ interactions. On average, breakfast inflation ratio was lower with the short (31.3\%) than with the long (55.0\%) RI. For the three-way interaction, with the short RI, girls' breakfast inflation ratio was lowest with reverse (18.4\%) and forward (21.1\%) prompts and highest with open (51.1\%) prompts, whereas boys' breakfast inflation ratio was lowest with open (15.4\%) and highest with the other three (36.5-41.0\%) prompts. With the long RI, girls' breakfast inflation ratio was lowest with meal name $(22 \cdot 0 \%)$ and highest with open $(76.0 \%)$ and reverse (78.5\%) prompts, whereas boys' breakfast inflation ratio was lowest with open (24.9\%) and highest with reverse $(76.3 \%)$ prompts.

Breakfast inflation ratio was substantially lower for breakfast located in the classroom (15.6\%) than for breakfast in the cafeteria $(70.7 \%)$. The prompt $\times$ location interaction was due to variation in the difference in inflation ratios between locations over the four prompts. The average inflation ratios (classroom, cafeteria) by prompt were as follows: forward (18.4, 57.8\%), meal name (13.2, 66.8\%), open $(10 \cdot 3,73 \cdot 4 \%)$ and reverse $(20 \cdot 6,84.9 \%)$.

Lunch. Table 4 also shows least squares means for lunch inflation ratio by RI, prompt and sex. The main effects of RI $(P=0.0005)$, prompt $(P=0.0045)$ and sex $(P<0.0002)$ were significant, as were interactions of $\mathrm{RI} \times$ prompt, prompt $\times$ sex 
S. D. Baxter et al.

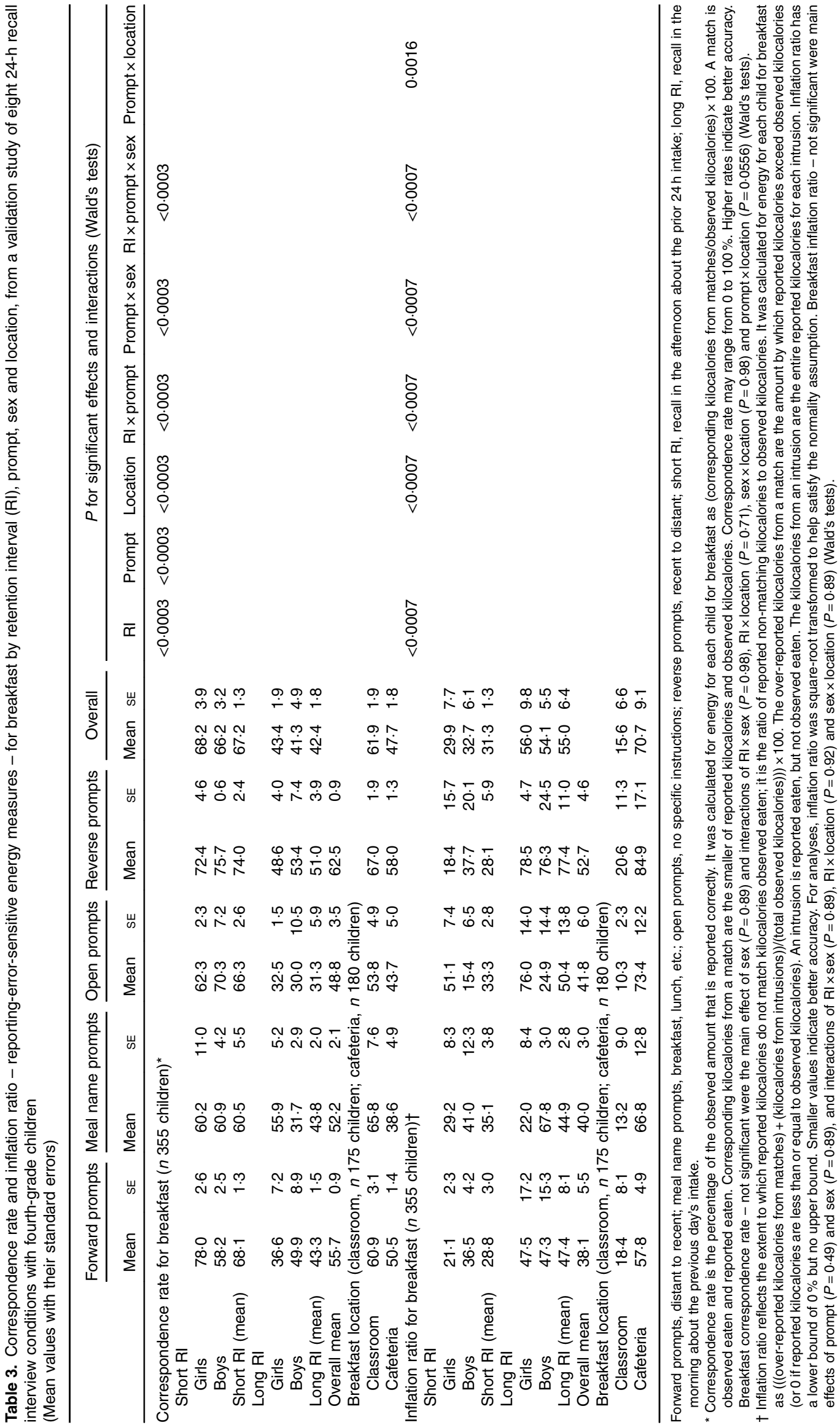


School-breakfast and school-lunch reports




and RI $\times$ prompt $\times$ sex (three $P$-values $<0 \cdot 0002$ ). Not quite significant, using a significance level that controls the false discovery rate at 0.05 , was the RIX sex interaction $(P=0.0628)$. On average, lunch inflation ratio was lower with the short (17.6\%) than with the long $(32.7 \%)$ RI. For the three-way interaction, with the short RI, girls' lunch inflation ratio was lowest with reverse (12.5\%) and meal name (13.9\%) prompts and highest with forward (20.7\%) prompts, whereas boys' lunch inflation ratio was lowest with forward (10.3\%) and highest with open $(32.4 \%)$ prompts. With the long RI, girls' lunch inflation ratio was lowest with meal name (16.3\%) and highest with reverse $(33.4 \%)$ prompts, whereas boys' lunch inflation ratio was lowest with reverse $(18.2 \%)$ and open (25.6\%) prompts and highest with meal name (56.3\%) and forward (63.5\%) prompts.

\section{Discussion}

In the current study, we analysed validation-study data ${ }^{(36)}$ to investigate RI and prompt effects on accuracy of fourth-grade children's reports of school-breakfast and school-lunch (obtained in 24hDRs) and to compare accuracy of schoolbreakfast reports by breakfast location (classroom; cafeteria). We used two different approaches to assess accuracy.

According to correspondence rate and inflation ratio - the reporting-error-sensitive measures - accuracy for energytransformed reports of intake was better with the short RI than with the long RI for breakfast reports and for lunch reports (in 24hDRs). This was not surprising as other validation studies have shown that recall accuracy is related to $\mathrm{RI}^{(28-34)}$. However, some of those validation studies obtained single-meal recalls, and some validation studies that obtained $24 \mathrm{hDRs}$ did not analyse accuracy for breakfast and lunch separately. This finding provides further evidence that recalls should be obtained as close in time to the eating events as possible.

In contrast, according to report rate - the conventional measure - accuracy did not depend on RI for breakfast or for lunch. Past comparisons of the reporting-error-sensitive and conventional approaches for analysing accuracy for reporting energy have found that report rate overestimates and provides a distorted picture of accuracy ${ }^{(37,54-56)}$. Thus, accuracy results for validation studies from the conventional measure (report rate) and from the reporting-error-sensitive measures (correspondence rate and inflation ratio) suggest different pictures of accuracy. This article's findings reinforce the importance of analysing recall accuracy in validation studies by examining which items or amounts were reported correctly rather than by simply dividing 'reported energy' by 'reference (e.g. observed) energy'. Aside from our publications ${ }^{(37,54-56)}$, the reporting-errorsensitive approach has been cited in some publications ${ }^{(58-60)}$, but used in few ${ }^{(61)}$.

Analyses of correspondence rate, and especially of inflation ratio, indicate that reporting accuracy appeared better for lunch than for breakfast. This result is likely related to the result that accuracy was better with the short than with the long RI. With the short RI (prior-24-h-afternoon), the approximate number of hours between eating breakfast and the $24 \mathrm{hDR}$ was five, and between eating lunch and the $24 \mathrm{hDR}$ was one. However, for the long RI (previous-day-morning), the approximate number of hours between eating breakfast and the $24 \mathrm{hDR}$ was twentyfive, and between eating lunch and the $24 \mathrm{hDR}$ was twenty-one. Thus, on average in this study, the number of hours between eating and the $24 \mathrm{hDR}$ for lunch $(11 \mathrm{~h})$ was less than for breakfast (15 h).

However, average report rates suggest that accuracy for breakfast appeared better than that for lunch. Thus, report rate provided results that were opposite of those from correspondence rate and inflation ratio concerning accuracy for breakfast $v$. lunch. Simply dividing 'reported energy' by 'observed energy' without accounting for which items or amounts were reported correctly distorts the picture of reporting accuracy.

For two past validation studies, we provided accuracy results of fourth-grade children's school-breakfast reports and schoollunch reports (obtained in 24hDRs) separately. In our 2007 article $^{(62)}$, when children reported after breakfast about the previous day's intake, school-lunch reports were more accurate than school-breakfast reports, as indicated by higher correspondence rates for lunch than for breakfast and lower inflation ratios for lunch than for breakfast; report rate was not assessed in the 2007 article. In our 2009 article ${ }^{(63)}$, accuracy for schoolbreakfast reports and school-lunch reports in $24 \mathrm{hDRs}$ was best when the RIs were shortest, and accuracy decreased as the RI increased. Specifically, as indicated by higher correspondence rates and lower inflation ratios, accuracy for school-breakfast reports was best for prior-24-h recalls conducted in the morning, and accuracy for school-lunch reports was best for prior-24-h recalls conducted in the afternoon, but report rates for schoolbreakfast reports and for school-lunch reports did not differ significantly by RI condition. However, in neither study did we manipulate prompts to examine their effects on recall accuracy.

For the current study, for each reporting-error-sensitive measure (correspondence rate, inflation ratio), for each of breakfast and lunch, the three-way $\mathrm{RI} \times$ prompt $\times$ sex interaction was significant, except for lunch correspondence rate for which the two-way RI $\times$ prompt interaction was significant. Interpretations of the three-way interactions are aided by the bar graphs in Fig. 1 and 2, which show least squares means for each combination of levels of the three factors. In these graphs, the correspondence rate was subtracted from 100 so that in each graph a lower value indicates better accuracy. The most prominent feature of the graphs is that for each sex, for almost all prompts, accuracy was better with the short RI than with the long RI. Exceptions from this differed for boys and girls. Consider the breakfast data (Fig. 1): for girls, the accuracy advantage of the short RI (in correspondence rate and in inflation ratio) disappeared with meal name prompts. For boys, the accuracy advantage of the short RI was mitigated (in correspondence rate) with forward prompts and (in inflation ratio) with forward and open prompts. Consider the lunch data (Fig. 2): accuracy was generally better with the short RI than with the long RI; however, irrespective of sex, the accuracy advantage of the short RI (in correspondence rate) was most prominent with open prompts and decreased or disappeared with reverse prompts. For girls, the accuracy advantage (in inflation ratio) of the short RI was mitigated with forward and meal name prompts. For boys, the accuracy advantage 



Fig. 1. Breakfast correspondence rate and breakfast inflation ratio, each for the two-way retention interval $(\mathrm{RI}) \times$ prompt interaction. The heights of the bars represent averages (per RI-prompt-sex combination) of the correspondence rate subtracted from 100 (top row) and of inflation ratio (bottom row), so that in all cases lower heights represent better accuracy. $\square$, Short Rl; $\square$, long Rl; the four categories along the horizontal axis are the four prompts.
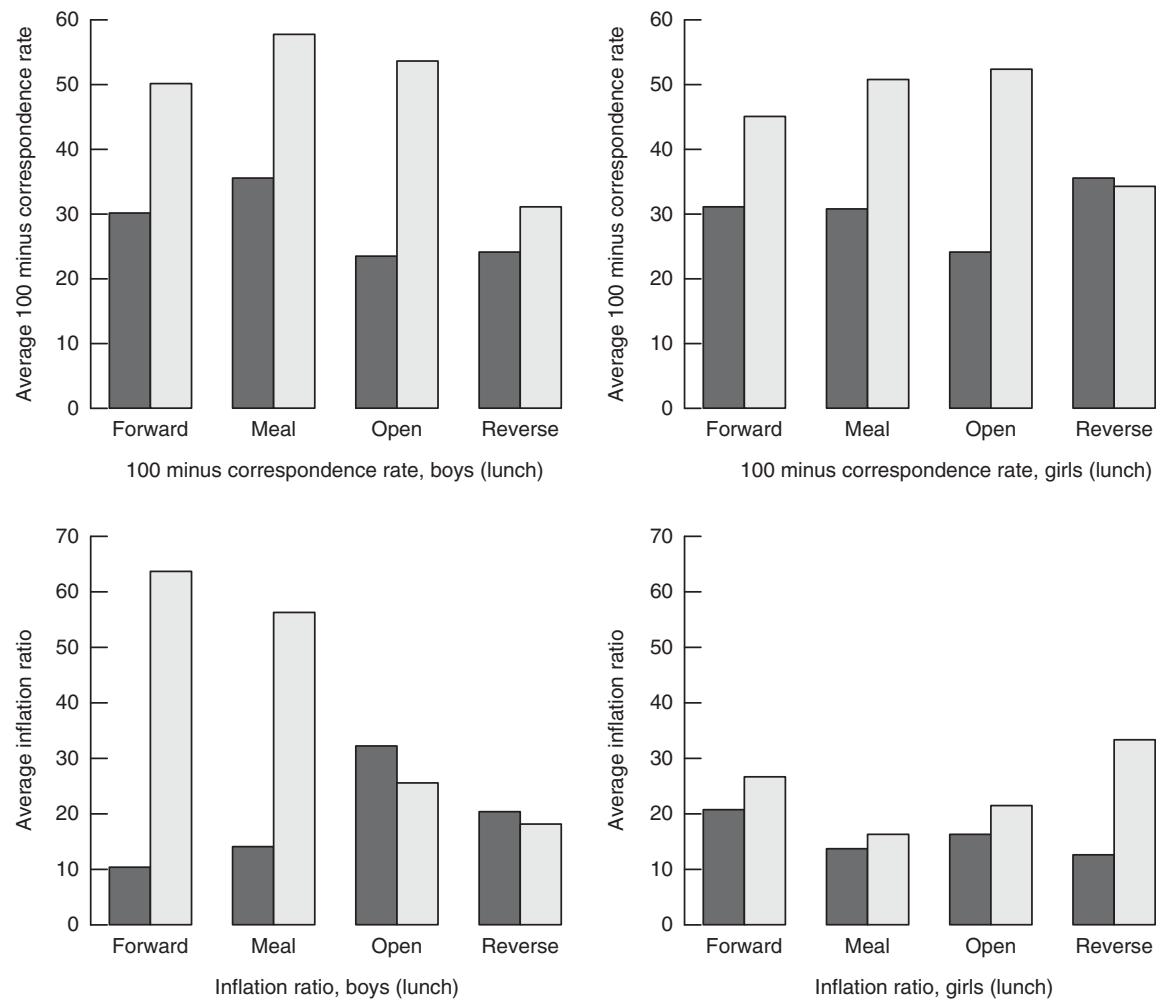

Fig. 2. Lunch correspondence rate and lunch inflation ratio, each for the two-way retention interval (RI) $\times$ prompt interaction. The heights of the bars represent averages (per RI-prompt-sex combination) of the correspondence rate subtracted from 100 (top row) and of inflation ratio (bottom row), so that in all cases lower heights represent better accuracy. $\square$, Short Rl; $\square$, long Rl; the four categories along the horizontal axis are the four prompts. 
(in inflation ratio) was only substantial for forward and meal name prompts. These results do not provide a clear basis for recommendations concerning prompts. Particular prompts may work differently for boys and for girls.

There was a relationship between children's breakfast accuracy and location of school breakfast. The reporting-errorsensitive measures - correspondence rate and inflation ratio - showed that, regardless of prompt, children's reporting accuracy was better for breakfast in the classroom than for breakfast in the cafeteria. Yet report rate communicated a very different picture: the average report rate was somewhat closer to $100 \%$ (i.e. more accurate) for breakfast located in the cafeteria than for breakfast located in the classroom for three of the four prompts. With customary interpretation that report rates closer to $100 \%$ are better, the accuracy results by breakfast location were opposite for the reporting-error-sensitive measures and the conventional measure.

Few studies have examined the relationship between children's dietary recall accuracy and school-breakfast location. In our 2009 study $^{(63)}$, none of correspondence rate, inflation ratio or report rate was related to accuracy of school-breakfast reports by school-breakfast location.

For the current study, there are several possible explanations for recall accuracy, indexed by the reporting-error-sensitive measures, to have been better for breakfast located in the classroom than in the cafeteria. The cafeteria environment was often noisier and more chaotic than the classroom environment; the calmer classroom environment may have helped those children be more mindful of their food intake. Children had more breakfast options when breakfast was located in the cafeteria than in the classroom. For example, in the cafeteria, children could often choose between a hot (e.g. sausage biscuit) and cold (e.g. ready-to-eat cereal) option, whereas in the classroom often only one option was available. Perhaps having more options in the cafeteria affected children's recall accuracy.

We conducted post hoc analyses on lunch data with breakfast location as a variable to determine whether recall accuracy for lunch was related to breakfast location. Results showed that for no response variable was lunch accuracy significantly related to breakfast location: report rate (unadjusted $P=0 \cdot 1779$ ), correspondence rate (unadjusted $P=0.9385$ ), inflation ratio (unadjusted $P=0 \cdot 2089$ ). Thus, our supposition in the introduction that different school breakfast locations could help children discriminate breakfast and lunch, and thereby improve recall accuracy, appears to not be supported.

The distributions of the 125 school breakfast non-reporters and the seventy-one school lunch non-reporters over conditions deserve discussion. Concerning RI, for breakfast, there were 1.3 times as many meal non-reporters with the long RI than with the short RI (seventy-one $v$. fifty-four). For lunch, there were twice as many meal non-reporters with the long RI than with the short RI (forty-seven $v$. twenty-four). This is consistent with findings that recall accuracy for children whose reports satisfied the criteria was worse with the long RI than with the short RI. Concerning prompt, meal non-reporters were distributed across all four prompts for breakfast and for lunch (see Table 1). It is notable that some children did not report meals even when meal name prompts were used. (With meal name prompts, children were directly asked 'Did you eat breakfast?' and 'Did you eat lunch?'). With regard to sex, for breakfast the meal non-reporters were sixty girls and sixty-five boys, and for lunch the meal non-reporters were thirty-one girls and forty boys. Thus, although sex was unrelated to reporting status for breakfast, it was somewhat related for lunch, with $1 \cdot 3$ times as many boys as girls being meal non-reporters. With regard to location, sixty children with breakfast located in the classroom and sixty-five children with breakfast located in the cafeteria were meal non-reporters; thus, location was not a factor.

One limitation of the validation study that provided data analysed for this article was that only fourth-grade children were recruited to participate. Another limitation is that children were not assigned randomly to breakfast location. A third limitation is that because amounts eaten were observed and reported in a qualitative manner (i.e. servings of standard school meal portions), kilocalorie measures are not precise. However, the same procedure was used throughout data collection for all meal observations, and for reported information by all 480 children interviewed. Furthermore, the same method was used to convert qualitative terms from meal observations and $24 \mathrm{hDR}$ into quantities of kilocalories. A fourth limitation is that data collection cells were not stratified by race/ethnicity; however, race/ethnicity was a control variable in analyses.

Strengths include those of the RI-and-prompt validation study. Specifically, reference information was obtained by direct meal observations. More children were recruited than needed for data collection, which made it difficult for children to determine who specifically was being observed, and to anticipate whether they would be interviewed. Rigorous and regular quality control was implemented for meal observations and interviews before and throughout data collection. Few past validation studies have examined the accuracy of children's school-breakfast reports and school-lunch reports (obtained during 24hDRs) separately.

In conclusion, in deciding to use dietary recalls, researchers and practitioners also decide which RI and prompts will be used for those recalls. To maximise recall accuracy, a short RI should be selected, whereas recommendations concerning the selection of specific prompts are less clear. Report rates provide a misleading picture of accuracy, and thus researchers should use reporting-error-sensitive measures to analyse validation-study data. In future validation studies, if meal location can be investigated as a potential source of systematic variability, it would be helpful to do so to accumulate information about this.

\section{Acknowledgments}

The authors thank the children and staff of the schools and districts (Richland 1, Lexington-Richland 5, Lexington 3, Lexington 4) in South Carolina for allowing data collection. The authors thank Kate K. Vaadi for help with data collection and scheduling, and Christina M. Devlin for help with scheduling.

This work was supported by the National Institutes of Health (NIH), National Heart, Lung, and Blood Institute (NHLBI) (grant 
R01HL103737, principal investigator S. D. B.). The NIH and the NHLBI had no role in the design, analysis or writing of this article. The content of this article is solely the responsibility of the authors and does not necessarily represent the official views of the NIH or the NHLBI. S. D. B.'s current and previous research has been funded by competitive grants from the NIH as well as the United States Department of Agriculture. She has served as a grant reviewer for the NIH and the Centers for Disease Control and Prevention. She is on the Board of Editors for the Journal of the Academy of Nutrition and Dietetics. A. F. S.'s research has been funded externally by competitive grants from the NIH. D. B. H.'s research has been funded by the South Carolina Department of Education and the University of South Carolina Research and Productivity Program

S. D. B. was principal investigator and wrote the manuscript. S. D. B., A. F. S. and D. B. H. contributed to the interpretation of findings. S. D. B. and A. F. S. contributed to the study design. C. H. G. and A. F. S. contributed to manuscript writing. C. H. G. contributed to data coding and conducted quality control for interviews. D. B. H. contributed to data analyses. J. A. R. programmed data files and analysed data. M. P. P., K. L. C. and A. L. S. contributed to data collection, data coding and data entry. All authors read and approved the final version of the manuscript.

C. H. G., J. A. R., M. P. P., K. L. C. and A. L. S. have no conflicts of interest to disclose.

\section{References}

1. US Department of Agriculture \& Economic Research Service (2015) The Food Assistance Landscape: FY 2014 Annual Report. Economic Information Bulletin No. EIB-137. http://www.ers.usda. gov/publications/eib-economic-information-bulletin/eib137.aspx (accessed December 2015).

2. US Department of Agriculture, Food and Nutrition Service \& Office of Research, Nutrition, and Analysis (2007) School Nutrition Dietary Assessment Study-III: Volume II: Student Participation and Dietary Intakes, Report, no. CN-07-SNDA-III. Alexandria, VA: US Department of Agriculture, Food and Nutrition Service \& Office of Research, Nutrition, and Analysis. http://www.fns.usda.gov/sites/default/files/SNDAIII-Vol2.pdf (accessed December 2015).

3. Academy of Nutrition and Dietetics (2014) Position of the Academy of Nutrition and Dietetics: nutrition guidance for healthy children ages 2 to 11 years. J Acad Nutr Diet 114, 1257-1276.

4. American Dietetic Association (2010) Position of the American Dietetic Association: local support for nutrition integrity in schools. J Am Diet Assoc 110, 1244-1254.

5. American Dietetic Association, School Nutrition Association \& Society for Nutrition Education (2010) Position of the American Dietetic Association, School Nutrition Association, and Society for Nutrition Education: comprehensive school nutrition services. J Am Diet Assoc 110, 1738-1749.

6. French SA \& Stables G (2003) Environmental interventions to promote vegetable and fruit consumption among youth in school settings. Prev Med 37, 593-610.

7. Hoelscher DM, Evans A, Parcel GS, et al. (2002) Designing effective nutrition interventions for adolescents. $J$ Am Diet Assoc 102, S52-S63.

8. US Department of Agriculture \& Food and Nutrition Service (2015) Local School Wellness Policy. http://www.fns.usda.gov/ tn/Healthy/wellnesspolicy.html (accessed December 2015).
9. Baranowski T, Baranowski J, Cullen KW, et al. (2003) Squire's Quest! Dietary outcome evaluation of a multimedia game. Am J Prev Med 24, 52-61.

10. Contento IR, Randell JS \& Basch CE (2002) Review and analysis of evaluation measures used in nutrition intervention research. J Nutr Educ Behav 34, 2-25.

11. Lytle LA, Dixon LB, Cunningham-Sabo L, et al. (2002) Dietary intakes of native American children: findings from the pathways feasibility study. I Am Diet Assoc 102, $555-558$.

12. Moore HJ, Ells LJ, McLure SA, et al. (2008) The development and evaluation of a novel computer program to assess previous-day dietary and physical activity behaviours in school children: the Synchronised Nutrition and Activity Program $^{\mathrm{TM}}$ (SNAP ${ }^{\mathrm{TM}}$ ). Br J Nutr 99, 1266-1274.

13. Receveur O, Morou K, Gray-Donald K, et al. (2008) Consumption of key food items is associated with excess weight among elementary-school-aged children in a Canadian First Nations Community. J Am Diet Assoc 108, 362-366.

14. Thiagarajah K, Fly AD, Hoelscher DM, et al. (2008) Validating the food behavior questions from the elementary school SPAN questionnaire. J Nutr Educ Behav 40, 305-310.

15. US Department of Agriculture, Food and Nutrition Service \& Office of Research, Nutrition, and Analysis (2007) School Nutrition Dietary Assessment Study-III: Volume II: Student Participation and Dietary Intakes, Executive Summary, Report, No. CN-07-SNDA-III. Alexandria, VA: US Department of Agriculture, Food and Nutrition Service \& Office of Research, Nutrition, and Analysis. http://www.fns.usda.gov/schoolnutrition-dietary-assessment-study-iii (accessed December 2015).

16. Wong SS, Boushey CJ, Novotny R, et al. (2008) Evaluation of a computerized food frequency questionnaire to estimate calcium intake of Asian, Hispanic, and non-Hispanic white youth. J Am Diet Assoc 108, 539-543.

17. McPherson Day RS, Hoelscher DM, Byrd-Williams C, et al. (2014) Validity and reliability of dietary assessment in schoolage children. In Handbook of Nutrition and Food, 3rd ed. pp. 569-623 [CD Berdanier, JT Dwyer and D Heber, editors]. Boca Raton, FL: CRC Press.

18. Baranowski T, Smith M, Baranowski J, et al. (1997) Low validity of a seven-item fruit and vegetable food frequency questionnaire among third-grade students. J Am Diet Assoc 97, 66-68.

19. Domel SB, Baranowski T, Davis HC, et al. (1994) Fruit and vegetable food frequencies by fourth and fifth grade students: validity and reliability. J Am Coll Nutr 13, 33-39.

20. Field AE, Peterson KE, Gortmaker SL, et al. (1999) Reproducibility and validity of a food frequency questionnaire among fourth to seventh grade inner-city school children: implications of age and day-to-day variation in dietary intake. Public Health Nutr 2, 293-300.

21. Baranowski T, Islam N, Baranowski J, et al. (2002) The food intake recording software system is valid among fourth-grade children. J Am Diet Assoc 102, 380-385.

22. Baxter SD, Thompson WO, Litaker MS, et al. (2002) Low accuracy and low consistency of fourth-graders' school breakfast and school lunch recalls. J Am Diet Assoc 102, 386-395.

23. Crawford PB, Obarzanek E, Morrison J, et al. (1994) Comparative advantage of 3-day food records over 24-hour recall and 5-day food frequency validated by observation of 9- and 10-year-old girls. J Am Diet Assoc 94, 626-630.

24. Todd KS \& Kretsch MJ (1986) Accuracy of the self-reported dietary recall of new immigrant and refugee children. Nutr Res 6, 1031-1043. 
25. Baxter SD, Thompson WO, Smith AF, et al. (2003) Reverse versus forward order reporting and the accuracy of fourthgraders' recalls of school breakfast and school lunch. Prev Med 36, 601-614.

26. Neuhouser ML (2014) Methodologies and tools for dietary intake assessment. In Handbook of Nutrition and Food, 3rd ed. pp. 555-567 [CD Bernadier, JT Dwyer and D Heber, editors]. Boca Raton, FL: CRC Press.

27. Moshfegh AJ, Rhodes DG, Baer DJ, et al. (2008) The US Department of Agriculture Automated Multiple-Pass Method reduces bias in the collection of energy intakes. Am J Clin Nutr 88, 324-332.

28. Baxter SD, Hardin JW, Guinn CH, et al. (2009) Fourth-grade children's dietary recall accuracy is influenced by retention interval (target period and interview time). J Am Diet Assoc 109, 846-856.

29. Baxter SD, Hitchcock DB, Guinn CH, et al. (2013) A pilot study of the effects of interview content, retention interval, and grade on accuracy of dietary information from children. J Nutr Educ Behav 45, 368-373.

30. Baxter SD, Hitchcock DB, Guinn CH, et al. (2014) A validation study concerning the effects of interview content, retention interval, and grade on children's recall accuracy for dietary and/or physical activity. J Acad Nutr Diet 114, 1902-1914.

31. Baxter SD, Smith AF, Litaker MS, et al. (2006) Body mass index, sex, interview protocol, and children's accuracy for reporting kilocalories observed eaten at school meals. $J \mathrm{Am}$ Diet Assoc 106, 1656-1662.

32. Baxter SD, Smith AF, Litaker MS, et al. (2004) Recency affects reporting accuracy of children's dietary recalls. Ann Epidemiol 14, 385-390.

33. Baxter SD, Thompson WO, Davis HC, et al. (1997) Impact of gender, ethnicity, meal component, and time interval between eating and reporting on accuracy of fourth-graders' self-reports of school lunch. J Am Diet Assoc 97, 1293-1298.

34. Moore GF, Tapper K, Murphey S, et al. (2007) Validation of a self-completion measure of breakfast foods, snacks and fruits and vegetables consumed by 9- to 11-year-old schoolchildren. Eur J Clin Nutr 61, 420-430.

35. Baxter SD, Smith AF, Guinn CH, et al. (2003) Interview format influences the accuracy of children's dietary recalls validated with observations. Nutr Res 23, 1537-1546.

36. Baxter SD, Smith AF, Hitchcock DB, et al. (2015) Effectiveness of prompts on fourth-grade children's dietary recall accuracy depends on retention interval and varies by gender. $J$ Nutr 145, 2185-2192.

37. Smith AF, Baxter SD, Hardin JW, et al. (2007) Conventional analyses of data from dietary validation studies may misestimate reporting accuracy: illustration from a study of the effect of interview modality on children's reporting accuracy. Public Health Nutr 10, 1247-1256.

38. Neter J, Kutner MH, Nachtsheim CJ, et al. (1996) Applied Linear Statistical Models, 4th ed. Chicago, IL: Irwin.

39. Winer BJ (1991) Statistical Principles in Experimental Design, 3rd ed. New York, NY: McGraw-Hill.

40. Federal Register, Department of Agriculture \& Food and Nutrition Service (2012) 7 CFR Parts 210 and 220. Nutrition Standards in the National School Lunch and School Breakfast Programs; Final Rule (Vol. 77, No. 17, Part II). http:// childnutrition.ncpublicschools.gov/news-events/school-mealnutrition-standards/regulation-and-guidance/nutrition-standards. pdf (accessed December 2015).

41. Bartfeld J \& Kim M (2010) Participation in the school breakfast program: new evidence from the ECLS-K. Soc Serv Rev 84, 541-562.
42. Bernstein LS, McLaughlin JE, Crepinsek MK, et al. (2004) Evaluation of the School Breakfast Program Pilot Project: Final Report. Nutrition Assistance Program Report Series No. CN-04SBP, Project Officer: Anita Singh, US Department of Agriculture, Food and Nutrition Service, Office of Analysis, Nutrition, and Evaluation, Alexandria, VA. http://www.fns.usda.gov/evaluation-school-breakfast-program-pilot-project

(accessed December 2015).

43. Baxter SD, Thompson WO \& Davis HC (2001) Trading of food during school lunch by first- and fourth-grade children. Nutr Res 21, 499-503.

44. Baranowski T, Dworkin R, Henske JC, et al. (1986) The accuracy of children's self-reports of diet: family health project. J Am Diet Assoc 86, 1381-1385.

45. Simons-Morton BG \& Baranowski T (1991) Observation in assessment of children's dietary practices. J Sch Health $\mathbf{6 1}$, 204-207.

46. Buzzard M (1998) 24-hour dietary recall and food record methods. In Nutritional Epidemiology, 2nd ed. pp. 50-73 [W Willett, editor]. New York, NY: Oxford University Press.

47. Baxter SD, Thompson WO, Litaker MS, et al. (2003) Accuracy of fourth-graders' dietary recalls of school breakfast and school lunch validated with observations: in-person versus telephone interviews. J Nutr Educ Behav 35, 124-134.

48. Shaffer NM, Baxter SD, Thompson WO, et al. (2004) Quality control for interviews to obtain dietary recalls from children for research studies. J Am Diet Assoc 104, 1577-1585.

49. Smith AF, Jobe JB \& Mingay DJ (1991) Retrieval from memory of dietary information. Appl Cognit Psychol 5, 269-296.

50. Smith AF (1991) Vital and Health Statistics, Series 6: Cognitive Processes in Long-term Dietary Recall, No. 4. Hyattsville, MD: National Center for Health Statistics.

51. Regents of the University of Minnesota (2014) Nutrition Coordinating Center Food and Nutrient Database. http://www.ncc. umn.edu/products/database.html (accessed December 2015).

52. Samuelson G (1970) An epidemiological study of child health and nutrition in a northern Swedish county. II. Methodological study of the recall technique. Nutr Metab 12, 321-340.

53. Reynolds LA, Johnson SB \& Silverstein J (1990) Assessing daily diabetes management by 24 -hour recall interview: the validity of children's reports. J Pediatr Psychol 15, 493-509.

54. Baxter SD, Guinn CH, Royer JA, et al. (2010) Shortening the retention interval of 24-hour dietary recalls increases fourthgrade children's accuracy for reporting energy and macronutrient intake at school meals. J Am Diet Assoc 110, 1178-1188.

55. Baxter SD, Smith AF, Hardin JW, et al. (2007) Conclusions about children's reporting accuracy for energy and macronutrients over multiple interviews depend on the analytic approach for comparing reported information to reference information. J Am Diet Assoc 107, 595-604.

56. Baxter SD, Smith AF, Hardin JW, et al. (2007) Conventional energy and macronutrient variables distort the accuracy of children's dietary reports: illustrative data from a validation study of effect of order prompts. Prev Med 44, 34-41.

57. Benjamini Y \& Hochberg Y (1995) Controlling the false discovery rate: a practical and powerful approach to multiple testing. J R Stat Soc Series B Methodol 57, 289-300.

58. Duffey KJ \& Popkin BM (2013) Causes of increased energy intake among children in the U.S., 1977-2010. Am J Prev Med 44, e1-e8.

59. Hebert JR, Hurley TG, Steck SE, et al. (2014) Considering the value of dietary assessment data in informing nutrition-related health policy. Adv Nutr 5, 447-455.

60. Gleason PM, Harris J, Sheean PM, et al. (2010) Publishing nutrition research: validity, reliability, and diagnostic test assessment in nutrition-related research. J Am Diet Assoc 110, 409-419. 
61. Nielsen KM (2009) Comparison of children's 24-hour recalls and food records using two method of analysis. Master Thesis, University of Nevado, Reno, NV. http://search.proquest.com/ docview/304946692 (accessed December 2015).

62. Baxter SD, Royer JA, Hardin JW, et al. (2007) Fourth-grade children are less accurate in reporting school breakfast than school lunch during 24-hour dietary recalls. J Nutr Educ Behav 39, 126-133.

63. Baxter SD, Guinn CH, Royer JA, et al. (2009) Accuracy of children's school-breakfast reports and school-lunch reports (in 24-h dietary recalls) differs by retention interval. Eur J Clin Nutr 63, 1394-1403. 